\title{
THE EPISTEMOLOGY OF MODEST ATHEISM
}

\author{
J. L. SCHELLENBERG \\ Mount Saint Vincent University
}

\begin{abstract}
Distinguishing between the old atheism, the new atheism, and modest atheism, and also between belief and acceptance, and belief and acceptance tokens and types, I defend the disjunctive view that either modest atheistic belief or modest atheistic acceptance, construed as type, is today epistemically justified in the context of philosophical inquiry. Central to my defence is a deductive version of the hiddenness argument and an emphasis on the early stage of philosophical inquiry that we presently occupy.
\end{abstract}

I begin with distinctions between what I shall call the old atheism, the new atheism, and modest atheism. The old atheism, exemplified by J. L. Mackie in his book The Miracle of Theism (1982) and by hundreds of others, especially from the Enlightenment on, has the following three features. It is narrowly personalist (that is, concerned only with a conception of God as person, or something like a person); it is commonly supported by philosophical arguments; and it is purely negative (that is to say, restricted to denying the existence of a personal God).

The new atheism, exemplified by Richard Dawkins in his book The God Delusion (2006) and by at least three others (though many more are cheering the 'four horsemen' on), lacks each of these features. For it is quite generally opposed to the idea of transcendent or supernatural realities and thus has a broader than personalist focus; it tends, moreover, to depend on appeals, implicit or explicit, to a certain positive metaphysics, namely, scientific naturalism (hereafter: naturalism); and because of the previous point, it cannot be said to restrict itself to a purely negative claim.

In my view, there are a number of things wrong with the new atheism, and its epistemological approach - to the extent that it has one - is flawed. Ideology-infused bellicosity too often takes the place of careful reasoning 
here. If atheism depends on such a flawed epistemology, then atheism should be rejected by philosophers. Happily (or unhappily, depending on your view), atheism does not depend on it, and so we cannot turn that conditional into a sound instance of modus ponens. Most obviously, there is also the less flamboyant but more formidable old atheism, whose arguments against theism and in support of its own negative claim have, over the past few centuries, been something of a thorn in the side for theistic philosophers.

When I was young, I identified with the old atheism, and sought to enlarge its store of arguments with new philosophical arguments from hiddenness, horrors, and free will (yes, there is a free will offence as well as a free will defence). But in the last decade or so I have moved to a more nuanced position which I shall here call modest atheism.

At first glance modest atheism may seem somewhat less than modest, for it does not reject any of the three features distinguishing old atheism, instead adding to them. (It might therefore also be called old atheism plus.) But what it adds makes for an overall stance that includes a modest, even sceptical strain. Modest atheism supposes to be false a certain precise affirmative proposition about the existence of an ultimate divine reality influential in both western philosophy and western religion - that the divine exists as person and actor - while regarding it as epistemically possible (by which I mean 'not justifiedly deniable') that some other affirmative proposition about the existence of a religious ultimate, perhaps one unknown or even unknowable to us today, should one day prove to be true. While it closes the book on personal theism, it is open - and explicitly open - to the discovery of other forms of divine reality. And it is so (quite ironically given the preoccupations of the new atheism, whose opposition in the name of science to all things religious we have already noted) at least partly in light of what science teaches us about our place in evolutionary time, a place which, when we make the appropriate transition from human to scientific timescales, we will see to be at the very beginning of intelligent inquiry on our planet, which our self-important species has grown accustomed to treating as though it were the end.

I take it that the old atheism is not thus open. Indeed, here we hit on an assumption apparently shared by the old and the new atheists. This assumption is that there is truth in religion only if something like personal theism is true. If this assumption is not being made by the old atheists, then how shall we explain the fact that, after reaching atheism, 
they venture no further in religious investigation? Most old atheists, just like new atheists, are naturalists, even if they don't crudely conflate atheism with naturalism at the conceptual level. And if this assumption is not being made by the new atheists, then how shall we explain the fact that they do tend to conflate atheism with naturalism?

Modest atheism, therefore, is unlike each of the other atheisms in its openness to nontheistic religious discoveries, perhaps ones occurring only in the far future. It does not rule them out. That is to say, it is more modest.

In this essay I want to defend the claim that modest atheism is in good shape, epistemologically. But to prepare the way for this defence some more distinctions are needed. We need to distinguish between atheism (of any kind) as proposition, as belief, and as acceptance, and then also between belief and acceptance tokens and types.

Much of what I have said so far could be understood on the assumption that atheism is a proposition or claim of some kind - in the case of modest atheism, the proposition that no personal God exists but some other depiction of the divine may someday prove correct. In philosophical discussions of whether atheism is true this propositional interpretation is clearly being applied. For only propositions are literally true or false. But we might also - and sometimes do - ask whether so-and-so's atheism is well grounded or justified, or speak (as I did earlier) of a person's state of mind as exemplifying atheism. And here we are usually instead thinking about a certain individual's belief that an atheistic proposition is true. But there is yet a third possibility, which tends to be overlooked in philosophy today but will become more salient as the distinction in epistemology between belief and acceptance is further clarified and utilized - a process which, perhaps optimistically, I think is well underway. This is that the atheism of a philosopher such as myself, or of any person, may amount to an acceptance of the relevant proposition rather than belief of it. In close but not quite complete conformity with what L. Jonathan Cohen says about that distinction in his excellent book on the subject (1992), I suggest that the term 'acceptance' is most helpfully used to name what is described when we speak of in a fully voluntary manner forming and maintaining a policy of treating a proposition as true, using it as a basis for inference. A corollary is that the term 'acceptance' ought to be distinguished from 'belief,' which rather names a less than fully voluntary disposition (or set of dispositions) such as the involuntary disposition Cohen himself identifies with belief: namely, the disposition 
to feel a proposition true in relevant circumstances. It seems clear that sometimes the 'position' of a philosopher on this issue or that should be understood in terms of that philosopher's accepting a certain proposition rather than in terms of belief. And perhaps at an early stage of investigation, of the sort I have said we will see ourselves to be in when we fully absorb scientific timescales, there will often be occasion for acceptance even if not for belief.

Suppose, then, that we have seen the differences between atheism as proposition, as belief, and as acceptance. Suppose also that we have noticed that the conditions of belief's justification might be different from those attaching to the justification of acceptance (more on this later), and accordingly that the epistemology of atheism as belief might be different from the epistemology of atheism as acceptance. There is still - and finally - the distinction between belief and acceptance tokens and types to take note of.

This is really a distinction between different senses of the expressions 'belief that p' and 'acceptance that p'. Sometimes it is a certain way of believing or accepting, the belief or acceptance that $\mathrm{p}$, that we have in mind when we use such an expression, and to use it correctly we need not presuppose that this belief or acceptance is realized in anyone (even if its appropriateness to this or that mental or social context is discussed); but in another sense what we may have in mind is his or her belief or acceptance that $\mathrm{p}$, and in evaluating the belief or acceptance thus understood we evaluate the person who exemplifies it by way of assessing their relevant dispositions (the dispositions involved in their coming to, or not ceasing to, include in their mental repertoire the belief or acceptance in question). In the former abstract case what we have is a belief or acceptance type; in the latter concrete case it is a belief or acceptance token.

In considering the justification of a belief or acceptance type in connection with the existence of God what we are looking for is a worthiness of instantiation that abstract discussion of whether belief or acceptance is best among available responses (either the best or $a$ best, and either way such as cannot be exceeded) will help us discern; such discussion, in my view, is the task of philosophers, and I shall be engaging in it here. Whereas in evaluating belief or acceptance tokens the relevant desideratum is what we may call responsibility, which amounts to something like the proper fulfilment of all relevant duties and the exercise of intellectual virtue in the formation and maintenance 
of belief or acceptance by the relevant believer or accepter. There is this connection between the two levels of evaluation that may be noted: if one declares a certain response type to be unjustified within a certain context and so unworthy of being instantiated, then one will also think that, other things being equal, investigation of the most responsible and virtuous sort will in that context lead to such a response type not being instantiated by the investigator, and so the investigator will, in the token sense, not be justified in exhibiting that response. But there are obviously many variables that can prevent facts about type and token justifications from matching up here, such as persistent controversy over type justification, the amounts of information particular investigators have about the results of formal inquiry, and so on.

So when I say that I mean to defend the thesis that modest atheism is in good shape, epistemologically, do I have in mind atheism as belief or acceptance, and will it be belief or acceptance as token or type? What I've just said about the task of philosophers leads me to a focus on response types. And the distinction between belief and acceptance affords the defence of modest atheism some flexibility here, which I intend to make use of. The view I shall defend is accordingly the following: that either modest atheistic belief or modest atheistic acceptance, construed as type, is today justified (i.e., worthy of being instantiated) within the context of philosophical inquiry about things religious. Since this is the view I mean to defend, it may from here on be assumed that when I speak of atheistic belief or acceptance I am speaking of a certain type of stance. I myself think modest atheistic belief is justified, but I shall argue only for the weaker disjunctive claim. And the final result I'm aiming at is indeed a successful defence - in a short paper I cannot hope to establish my conclusion but I do intend to advance its cause, to put it in a more favourable light.

Even so, I have my work cut out for me. How will the defence proceed? I want now to suggest that here too modest atheism can do something to earn its name, for it is also in a way modest in the sort of reasoning it uses to support itself. At first, you will want to say, once again, that what I count as modesty here is really immodesty! For the reasoning I have in mind is deductive reasoning - and haven't we long since come to appreciate that deductive arguments for the nonexistence of God are hopelessly over-optimistic? Hasn't atheistic philosophy of religion in the past few decades come to focus, much more modestly and appropriately, on inductive reasoning, such as the probabilistic reasoning of William Rowe or Paul Draper (Howard-Snyder, ed. 1996)? 
My reason for focusing on deductive arguments, and daring to call what I am doing modest, is in part bound up with what is required to justify belief on big issues such as those of philosophy at an evolutionarily early stage of inquiry such as our own. I would not say that no philosophical beliefs at all can presently be justified; that way an inquiry-stultifying scepticism looms. But I do say that a justification for philosophical belief is, at an early stage of inquiry, much easier to provide where compelling grounds, such as those embodied by an apparently sound deductive argument, are available. In the absence of compelling grounds, in particular where probabilistic arguments alone are given, I think inquirers should be much more reluctant to claim justification for philosophical belief as opposed to, say, an increase in the probability that a certain philosophical claim is true. My modesty consists, in part, in this reluctance.

But my immodesty, you may now say, consists in my suggestion that the high bar I have set up can be reached in the case of atheism! Well, is it any more modest to assume that no other good deductive arguments against the existence of God will be discovered than have already been discovered at a relatively early point in the evolution of intelligence, say, 1982 ? This, it appears, is what any pre-emptive argument of the sort suggested by the critic must assume. In any case, here it is important to recall my disjunctive approach, which will be satisfied even if only acceptance of the proposition put forward by the modest atheist can in some way be justified. Deductive arguments, as we will see, may have a role to play in relation to acceptance too.

So which deductive argument(s) for the nonexistence of God will I advance? Well, when I saw the line-up of topics and speakers gracing the conference on the epistemology of atheism for which this paper was written, I noticed that the hiddenness argument was to receive considerable discussion. Since - as I note perhaps without modesty but I think truthfully - I was responsible for getting that way of reasoning into discussion a couple of decades ago (Schellenberg 1993), I decided that I might as well jump on the bandwagon and convey how I view the hiddenness argument at present, using this to develop my case. But there is another reason for focusing on the hiddenness argument here. Since it is a relatively new argument, driven in part by secularization processes that have had some considerable influence in the last few centuries, it fits nicely with my emphasis on how we are still very much at the beginning 
of things where religion and its discussion are concerned and nowhere near the end.

But what matters here is whether the hiddenness argument is a good argument, capable of justifying atheistic belief or acceptance. So let's have a look. There are various ways of formulating the argument. The way I have chosen to use is the following:

(1) If no perfectly loving God exists, then God does not exist.

(2) If a perfectly loving God exists, then there exists a God who is always open to personal relationship with any finite person.

(3) If there exists a God who is always open to personal relationship with any finite person, then no finite person is ever nonresistantly in a state of nonbelief in relation to the proposition that God exists.

(4) If a perfectly loving God exists, then no finite person is ever nonresistantly in a state of nonbelief in relation to the proposition that God exists (from $2 \& 3$ ).

(5) Some finite persons are or have been nonresistantly in a state of nonbelief in relation to the proposition that God exists.

(6) No perfectly loving God exists (from $4 \& 5$ ).

(7) God does not exist (from 1 \& 6).

The phraseology here is a bit loose in places, but if one wants to convey a clear first impression it helps not to weigh the argument down with numerous explanatory clauses, and we can tighten things up as we go along.

The first thing to notice about the argument is that the inferences at steps (4), (6), and (7) are clearly deductively valid. So we can focus on whether the premises should win our belief or acceptance.

Shall we go along with premise (1): if no perfectly loving God exists, then God does not exist? Well, the idea of a person-like God - which as I've noted is the idea of God that the modest atheist, like the old atheist, is concerned with - represents one way in which the religious idea of an ultimate reality has been interpreted by human beings. Notice also that it is only or mainly as a candidate for metaphysical and axiological ultimacy that God comes to have a place in the discussions of western philosophy. Now, as one might expect, given that word 'ultimate', God is commonly regarded as having all knowledge and all power - or at least as much as it makes sense to suppose a person like God could have. For 
the same reason of ultimacy, God is said to be the source of our existence and perfectly good. But God is also commonly said to be perfectly loving toward created beings. And this attribute is at least as obviously essential as the others. For the best love, love of the sort we rightly admire, is one of the most impressive features any person, man or woman, can display. Perhaps it is one of the results of recent cultural evolution that we can now see this more clearly than humans once did. How could a candidate for 'greatest possible person' be anything but a fraud if it weren't always possessed of the greatest possible love? Whatever stunning attributes it displayed, we would then be able to imagine an even greater person, who was perfectly loving. It seems incumbent, therefore, on everyone who today reflects on the existence of God to acknowledge that if God exists, God is perfectly loving. Christians of course have specially emphasized this attribute but for all theists and atheists in philosophy there is good reason to do so.

Let's move on, then, to premise (2): if a perfectly loving God exists, then there exists a God who is always open to personal relationship with any finite person. That phrase 'personal relationship' should at this point be tightened up a bit: what I have in mind is a conscious and (positively) meaningful relationship. I should also acknowledge a point that, once acknowledged, will remain tacit: namely, that the scope of premise (2) is restricted to finite persons who are relevantly capable, where the relevant capacities are cognitive and affective capacities sufficient to be able at the time in question to be in a meaningful conscious relationship with God - such things as a capacity then to feel the presence of God, recognizing it as such; a capacity to exhibit attitudes of trust, gratitude, and obedience to God, and so on.

Now, some theists might be inclined to resist this premise because of a prior commitment to a religious scripture or creed incompatible with it or in tension with it. Isn't the God of the Bible, for example, often portrayed as somewhat distant relationally? But none of this can be relevant here where we are considering what the modest atheist must do to rise above epistemological suspicion. The modest atheist, who like the old atheist is working within a philosophical frame of reference, cannot be limited by theological assumptions which have been formed because of the need to find room for God in our world. It shouldn't need to be said, but in the present circumstances of inquiry in philosophy of religion, which is filled with believing philosophers, it has to be emphasized that philosophers cannot assume because of some consensus in their 
communities that God exists and so has only those qualities compatible with creating a world like ours, but must seek to be guided by reason when considering what a God would be like.

So what does careful reasoning, which seeks to be attentive to all that we humans have learned, tell us? Well, it makes it clear that people who admirably love you (and thus any who perfectly love you) are invariably open to a kind of personal relationship with you in which the two of you can interact meaningfully and consciously with each other. Indeed, since they love you in this way, they want to be close to you, and close in a way you can appreciate, so you can turn to them for advice or draw on their support or just feel them present with you when that's needed. (Of course if they admirably love you, they'll value being with you for its own sake, too.) Now, it's true that they won't force any of this on you, which is one reason why I only used the word 'open' when stating this premise. There is even room here for a sort of withdrawal within relationship. But if they aren't at least open to such relationship, it would be a mistake to say they admirably love you.

To see this with full clarity, imagine that you're listening to a friend, who's describing his parents: 'Wow, are they ever great - I wish everyone could have parents like mine, who are so wonderfully loving! Granted, they don't want anything to do with me. They're never around. Sometimes I find myself looking for them - once, I have to admit, I even called out for them when I was sick - but to no avail. Apparently they're just not open to a relationship with me right now. But it's so good that they love me as much and as beautifully as they do!' If you heard your friend talking like this, you'd think he was seriously confused. And you'd be right. His parents, if your friend's description of them is correct, could certainly be lots of other things - even impressive things, like the best corporate lawyer in the country and the President - but their attitude toward their son, whatever it is, does not include an admirable love.

I expect you'll see how all of this can be applied to God. A careful look at the concept of love should lead us to affirm that God is always open to personal relationship with each of $u s$ (or with each of the beings a God would or might create, whoever they are), if God exists and is perfectly loving - which is to say that premise (2) is true.

Now, so far I've been treating the concept of 'openness' to relationship as one we all understand, and at an intuitive level I'm sure this is the case. But as we move on to premise (3) - if there exists a God who is always open to personal relationship with any finite person, then no 
finite person is ever nonresistantly in a state of nonbelief in relation to the proposition that God exists - we will need to probe this concept a bit more carefully. So let's have a look at that word 'open' and how it behaves, logically speaking. In particular, let's note a sufficient condition of someone not being open in the relevant way:

\section{Not Open}

If a person $\mathrm{A}$, without having brought about this condition through resistance of personal relationship with person $B$, is at some time in a state of nonbelief in relation to the proposition that $\mathrm{B}$ exists, where $B$ at that time knows this and could ensure that A's nonbelief is at that time changed to belief, then it is not the case that B is open at the time in question to having a personal relationship with $A$ then.

Indeed, in such circumstances B (if B exists) is consciously preventing such a relationship from existing at that time. And if anything is obvious, it is that you cannot be open to a relationship in the relevant way while consciously preventing it! We can apply this to God, who of course possesses all relevant knowledge and ability: if any finite person is ever nonresistantly in a state of nonbelief in relation to God's existence, then there is no God always open to personal relationship with each finite person. Another way of putting that point gives us its contrapositive, which is premise (3): if there exists a God who is always open to personal relationship with each finite person, then no finite person is ever nonresistantly in a state of nonbelief in relation to the proposition that God exists.

So premise (3) seems quite clearly believable too. What about the last premise that needs to be checked, premise (5): some finite persons - and of course I have in mind human beings - are or have been nonresistantly in a state of nonbelief in relation to the proposition that God exists? Here again theology may tempt some theistic thinkers to suppose that our modest atheist is stepping outside the bounds of what should be believed. For might not any one of us be secretly resistant to a holy and demanding God, blinded to the motives that grip us? If so, then perhaps those who don't believe in God are, in a way, hiding from God. Might the proponent of the hiddenness argument have managed to get things backward in this way?

Notice first that she needn't be thinking about herself: perhaps other nonbelievers strike her as displaying nonresistance by the same standards that leave her questioning her own. Indeed, how could 
an investigator help noticing that some people who don't believe in God still have an admirable track record of investigation, and emotionally are, if anything, biased in favour of God? Some people who find that the evidence of argument and experience has taken belief in God away in midstream, as it were, in the midst of a strenuous religious life, would love to believe in God. What reason could someone have to say that they are resisting a relationship with God? It strains - and indeed breaks credulity. The evidence of nonresistance here can pile up in such a way that an honest inquirer judges it to be stronger than any counterevidence. Even if in such circumstances one thinks belief is unjustified because of new and unsuspected evidence that only future inquiry may reveal, clearly acceptance of a premise like (5) is justified given that the available evidence strongly supports it.

But even this is a weaker stance than is justified when we consider that we needn't stay focused on people who have thought about the existence of God and so have come within the range of motives for resisting it. Behind them, as it were, stretching into places far distant from any affected by Western culture, and also into times long ago, before humans had so much as conceived of an all knowing, all good and loving creator of the universe, we find evidence of individuals and communities who, though capable of possessing it, lacked belief in God, and obviously without ever having blinded themselves by resisting God in any way. How could there be resistance in such a case? The critic of (5) needs you to look away from all this evidence for nonresistant nonbelief. But to do so would be to fall prey to blindness of another kind.

The four premises of the hiddenness argument therefore seem clearly true. Since, as we have already seen, its three inferences are clearly valid, it follows that the argument seems clearly sound. Shall we therefore pronounce in favour of a belief or acceptance type of response to modest atheism?

Many philosophers will think that there could still be good reasons not to do so. For example, it may be said that there are powerful defeating objections showing one or another of the hiddenness argument's premises to be false or undercutting the justification for believing or accepting some such premise, or that there are equally strong arguments for theism to be weighed on the other side. Of course there isn't time here to examine closely all the reasoning I've just alluded to, but I think some illuminating general comments may still be made. 
Let's start with the last idea mentioned, that of equally strong arguments for theism. Even the most respected and spirited defenders of theism - take Richard Swinburne, for example - would shrink from a claim of the sort I have made on behalf of atheism: they would deny that there is a sound deductive proof of the truth of theism. And it is not hard to see why things should be harder here for theism than for atheism. If the existence of God requires that there be a person who is all powerful, all-knowing, perfectly good and loving, as well as the creator of the universe, then arguments for theism have the task of showing that all those conditions are present. But an argument for atheism need only show that one such condition is absent. (It may, for example, endeavour to show, as does the hiddenness argument, that perfect love is absent.) And the latter task might be expected to be the easier one. Indeed, it is notorious that the so-called theistic proofs are quite incapable of proving the existence of a being with the whole collection of properties possessed by the theistic God. (Even the ontological argument suffers from this incapacity, for although it purports to prove the existence of a greatest possible being, there is nothing in it to imply that a greatest possible being would be a greatest possible person, with such properties as knowledge and love.) Atheism does not have an analogous problem, and so we have the argumentative asymmetry.

What about the alleged defeating objections to premises of the hiddenness argument (or to our belief or acceptance of them)? I myself have done a thorough investigation of these objections and have found them all wanting. Indeed, I have created many new objections, in order to test the argument - with the same result. Now, it is of course true that others, especially philosophers who are theists, may disagree with me about one or another objection. But there is an important point to be noted here: namely, that such disagreement is frequently not philosophically grounded. Oftentimes I appear to be met by philosophers who are operating as theologians rather than as philosophers when they question the hiddenness argument.

Perhaps the clearest example of what I am talking about here appears near the end of a paper by the American philosophers Ted Poston and Trent Dougherty (2007: 196):

In the final analysis Schellenberg's argument fails because it envisions God as requiring too much: explicit, highly confident belief at all times. Fortunately, God is more generous. The Christian tradition attests that God will accept far less, he will 'meet us where we are'. 
Now, at first this may seem a relevant criticism. But listen to it carefully. When I first did so, I was truly startled: How could it be thought that the hiddenness argument depicts God as requiring belief of anyone and thus as ungenerous - with the implication that if the hiddenness argument were right about God, God would be leaving some - namely nonresistant nonbelievers - out in the cold, since they are unable to come up with what is required? After all, what the hiddenness argument clearly says is that God would generously offer belief - and the explicit relationship made possible thereby - to all, and so there would be no nonresistant nonbelievers in a world created by God. But then I saw that there is in Poston and Dougherty a tendency to assume that God exists and that whatever is being said about God must apply to the actual world - even when that comes in the context of an atheistic argument! Why else would it be supposed, when someone like me claims that God would favour explicit relationship, that those in the actual world who don't have what it takes to participate in such relationship are going to be left out? How could what God wants be too much unless creatures are unable to deliver it, and how could they be thought unable to deliver it unless we are thinking about our world instead of the world the hiddenness argument says would exist if God existed, in which all who are nonresistant believe?

Sadly, many allegedly philosophical objections to the hiddenness argument display a tendency similar to the one I claim to have found in Poston and Dougherty, even if not so brazenly. Within a philosophical context they can have no weight at all. In a philosophical context, where we have to let the voice of authority grow dim and think for ourselves about what a perfect personal being would be like, we may notice points that undermine the allegedly undermining objections to the hiddenness argument.

This holds also for a strategy quite popular today, known as 'sceptical theism,' which questions how we could justifiedly rule out the existence of unknown goods for the sake of which God is hidden. Accepting this move in the absence of some special theological bias or preconception seems to require forgetting what theism has got us talking about in the first place - an ultimate person. Consider by way of analogy a single man who marries and has children: Does this behaviour not rightly constrain the goods he is willing to pursue, at least insofar as he is a loving husband and father? Though when he was on his own he spent time with many female friends and was otherwise preoccupied with his own wideranging pursuits, travelling to far-flung regions of the earth for months 
at a time, shifting from place to place and from one activity to another, now things are different - and quite naturally and rightly so. Now he has a family to help provide for, to support in emotional and financial ways. He can't just take off for Greece or France for long periods at a time to indulge his own interests. Better, he has new interests which lead him happily to say no when invitations to do such things arise. Similarly with God, if God is to be regarded as a loving person - an ultimately loving person - who has created vulnerable finite persons to be the object of Divine love. The 'God' described by sceptical theists who may, for all we know, have purposes quite unrelated to us that require hiddenness from us is not an ultimately loving being at all. If construed personally, such a God is comparable to a limited or delinquent father or mother who simply can't or won't live up to the demands taken on board when the commitments of marriage and family are entered into.

I suggest, therefore, that on the basis of such considerations as I have briefly aired a great deal can be done to warrant, in the context of philosophical inquiry, setting aside our two counter-suggestions concerning equally strong arguments for theism and crippling objections to the hiddenness argument - without entering into many details of the associated reasoning.

But here's another counter-suggestion. Perhaps it will be suggested that there is also non-propositional experiential evidence to be considered here. Might not people who find themselves in the grip of suitably powerful experiences apparently of God have grounds for resisting the hiddenness argument - perhaps for saying that something is wrong with it, even if they know not what and though they lack any reasoning to offer against it? Recently philosophers of religion have been much concerned with questions of this sort, often defending an affirmative answer (Swinburne 2004, Alston 1991, Plantinga 2000). But the most that could conceivably be shown by this means is that theistic religious experience brings a non-atheistic response to the question of God's existence up to a level of worthiness for those inquirers who find themselves in the relevant experiential circumstances. It could not be shown that it brings an atheistic response down to a level of unworthiness for those who lack such non-propositional evidence.

Obviously there is no space here for a proper discussion of the epistemology of religious experience. But again some general comments suggest themselves which show that what I've found conceivable here is not actually to be expected, given the facts on the ground. For example, 
experiences apparently of God, to do the epistemic work required of them here, would have to be more forceful and also more discriminating than religious experiences often are. By 'discriminating' I mean they would need to clearly have theistic as opposed to any other religious content.

Now when we have perceptual experiences of other human persons our experiences commonly are discriminating in the relevant way: I see from the phenomenological details of my experience that it is John Greco before me and not Paul Draper or Roger Pouivet. Religious perceptual experiences are often much more fluid and malleable. It will, I suspect, be much easier in many cases to get someone to back down from the claim that the omni-God of traditional personalist theism was present to her to the claim that something powerfully transcendent was present to her than it will be to get me to back down from the claim that I saw John Greco to the claim that some human being or other stood before me. And if their degree of modesty about such things is tailored to our possible evolutionary immaturity, which here as elsewhere we are called to take into account, I think even philosophical inquirers in the grip of religious experience may accordingly often find its epistemic force less obvious and relevant than would be required to support the judgment we are considering. And we have not yet said anything about the problem, which arises for those who reject the argument I've just given, of religious experiential diversity.

So without too much discussion of details we can see that alleged proofs of theism, objections to the hiddenness argument, and suggestions about theistic religious experience may not gain much traction among those who earnestly and as philosophers investigate the question whether there is a God and, in that context, wonder what force the hiddenness argument should be regarded as having.

So what exactly am I proposing - that a belief response to modest atheism is justified for philosophers thinking about the existence of God, or that acceptance is? I will provide some more defence for each of the disjuncts of the disjunction suggested here in turn, hoping to impress each relevant investigator with at least one of my arguments and thus successfully to defend the disjunction in relation to everyone.

Let's start with belief. Each of the premises and also each of the inference claims of the hiddenness argument can be made to appear worthy of belief, and the counter-suggestions we have considered seem not obviously capable of diminishing this justification for the belief that the theistic God does not exist. Now, of course, we have been unable 
here to examine many details of those counter-arguments; but nor have we been able to examine other important deductive arguments for atheism, which, as I have maintained elsewhere (Schellenberg 2007), can be combined with the hiddenness argument to produce an even more forceful case for atheistic belief. A definitive outcome is, for these reasons, not in the cards today but I still conclude that atheistic belief in the part of philosophical inquiry concerning God has been made defensible, or more defensible, by my arguments in this paper - especially since it is a modest atheism that I have in mind, open to the idea that other conceptions of the divine demand inquiry.

But precisely this modesty, and its rootedness in scientific facts about our place in time, an objector may now wish to query more closely in an attempt to overturn my conclusion about atheistic belief. Are we not 'in over our heads' when we reach a belief about the existence of God, given the vast diversity of arguments from perhaps better equipped future inquirers that we are in the nature of the case unable to sample? Elsewhere, I have defended such reasoning in relation to the broader idea that there is no ultimate divine reality (Schellenberg 2007). Why isn't it equally applicable to the narrower but equally profound claim that there is no personal God?

Well, modest atheism, let us remember, denies only the existence of a person-like ultimate: an omnipotent, omniscient, perfectly good and loving creator of the universe. It makes the negative claim that there is no such divine being. This is not nearly so ambitious or profound a claim as the positive claim that there is such a being, or even as the negative claim that there is no religious reality of any kind, for it has many fewer metaphysical consequences. Think of how thorough a story of the overall nature of things you could tell, knowing that there is a God! But if all you know is that there isn't a God, you've just ruled out one way things could be. Indeed, you've only ruled out one religious way things could be; many other religious ways things could be, with similar metaphysical implications, remain. And so there's no justification, given only modest atheism, for an endorsement of such profound metaphysical claims as that of naturalism - though many immodest theists are mistakenly inclined to see the latter as following from atheism.

It should also be noted that by seeking only to refute traditional theism, we remain 'close to home' and need to mobilize no more than certain concepts and considerations we already possess. For the basic idea of a personal God, as traditionally understood, extrapolates from certain 
basic facts about ourselves - our limited power, knowledge, goodness, love - and thus from human qualities we do already know something about even at the present stage of our development. All my claims in this paper about how such a God could be revealed to us are unaffected by the awareness that many other conceptions of the divine remain to be explored and may indeed be outside the range of our current powers of conceptualization.

Here's another thought worth considering in this context. (It's related to the last one in that it simplifies the atheist's job even further.) Some of my arguments can make use of insights that draw on recent findings, for example in psychology and feminist thought, where we find a natural connection between admirable love and commitment to relationship. Thus their claims need to be considered as contenders for the status of propositions quite 'clear' in themselves but only now becoming clear to us: that is, as representing the forward edge of new and positive evolutionary developments. If this can be shown for atheism but not for theism, then once more we see how arguments justifying modest atheistic belief may be available even given only our present resources, though the arguments for theism fall short.

Having said all that in defence of modest atheistic belief in philosophy, I think another interesting argument that can be made, if that defence fails, is for atheism's acceptability. Of course we would expect philosophers who believe atheistically to also act upon this belief in inquiry, but arguments for acceptance are arguments for something like acting on the modest atheistic claim even when you don't yet believe it. And here, as Cohen makes clear (1992), pragmatic considerations concerning the needs of inquiry may be importantly relevant.

So consider these facts. (1) Inquiry about religion in western philosophy has been going on for thousands of years, and for most of that time has almost obsessively focused on theism and things theistic, hardly ever venturing into the potentially vast regions beyond. (2) The latest report (Chalmers and Bourget 2013) has it that 73\% of philosophers today favour atheism. Now, the figure would surely be different if we restricted our concern to the opinions of so-called philosophers of religion, who are predominantly believing theists. But while it might be argued that this is deserving of notice on the grounds that philosophers of religion are the experts on religion in philosophy, we would need to set against this point the fact that most of these so-called philosophers of religion, again, have not ventured beyond theism in their investigations, 
and also the fact that (3) many of them are deeply motivated by loyalty to their religious communities, and so should perhaps be regarded as doing theology - even if philosophical theology - rather than philosophy (Draper \& Nichols 2013, Schellenberg 2009). Finally, we need to note as, in part, a consequence of points already made - that (4) acceptance of atheism does not in any way imply (as those suppose who erroneously think one must accept either theism or naturalism) that we are closing the door to the truth of religious claims. Indeed, we are opening it more widely than has ever been done before!

What should a philosopher say who seeks to be sensitive to all these facts - while sensitive also to our temporal position and unwilling to endorse atheistic belief - and who notices that the latest arguments for atheism are as apparently forceful as the hiddenness argument? I think she should favour the acceptance of atheism.

Now it can be difficult to achieve a proper balance: When do you accept a conclusion and when do you say we should wait for more evidence? Many philosophers today would say that we are rushing things if we accept that theism is false. I would suggest that we know enough to do so. The details theistic ideas contain allow inferences about what most fundamentally has value and how it is realized if this filling for the idea of an ultimate divine reality is realized - and also the inference to atheism to be made. And I say we should get on with exploring other fillings for the idea of a divine reality, leaving open the possibility that the latter is true and so neither believing nor accepting that it is false. I have named the more general proposition here, the proposition more general than theism, 'ultimism'. The idea is that even at this early stage of religious investigation we should draw conclusions where we can, to help keep inquiry moving, while being very careful not to foreclose inquiry where we shouldn't. The distinction I have suggested between the epistemic status of ultimism, which says only that there is a metaphysically, axiologically, and soteriologically ultimate reality of some kind, and that of its personalist elaboration seems to me to get this balance about right and to respond appropriately to the needs of inquiry concerning religion in philosophy. But if so, then even if modest atheistic belief is thought to be unjustified in the precincts of philosophy, atheistic acceptance can still be justified.

A concluding summary, then, might run as follows. Epistemological considerations can be seen to favour an atheistic response in philosophy to questions about God's existence when we consider our subject 
carefully, distinguishing between belief and acceptance, and in a context governed by scientific timescales. The sort of atheism that is thus justified is a modest atheism. It claims to have extinguished the light from, at most, one of the many facets of the concept of a Divine reality. And it makes this claim only after discovering arguments of seemingly compelling force. These arguments can be used to defend modest atheistic belief as the preferable response to questions about a personal God in the context of philosophical inquiry. And even if this conclusion were to be left unsecured, perhaps because of the demands of deep time scepticism, there would still be reason to take such arguments as justifying the acceptance of modest atheism at the present stage of religious inquiry. It seems, therefore, that a modern and modest atheism can acquit itself admirably at the bar of epistemological reason.

\section{BIBLIOGRAPHY}

Alston, William P. 1991. Perceiving God: The Epistemology of Religious Experience (Ithaca: Cornell University Press)

Cohen, L. Jonathan. 2006. An Essay on Belief and Acceptance (Oxford: Clarendon Press)

Dawkins, Richard. 2006. The God Delusion (New York: Houghton Mifflin)

Draper, Paul \& Ryan Nichols. 2013. 'Diagnosing Bias in Philosophy of Religion', The Monist, 96: 422-448

Howard-Snyder, Daniel, ed. 1996. The Evidential Argument from Evil (Indianapolis: Indiana University Press)

Mackie, J. L. 1982. The Miracle of Theism (Oxford: Clarendon Press)

Plantinga, Alvin. 2000. Warranted Christian Belief (Oxford: Oxford University Press)

Poston, Ted \& Trent Dougherty. 2007. 'Divine Hiddenness and the Nature of Belief', Religious Studies, 43 : 183-198

Schellenberg, J. L. 1993. Divine Hiddenness and Human Reason (Ithaca: Cornell University Press)

Schellenberg, J. L. 2007. The Wisdom to Doubt: A Justification of Religious Skepticism (Ithaca: Cornell University Press)

Schellenberg, J. L. 2009. 'Philosophy of Religion: A State of the Subject Report', Toronto Journal of Theology, 25: 95-110

Swinburne, Richard. 2004. The Existence of God, 2nd. ed. (Oxford: Oxford University Press) 